\title{
Finite Element Method Based Modeling for Tool Wear Prediction in Orthogonal Cutting Process
}

\author{
A. Hatem Ali ${ }^{*}$, B. Tarek M. El Hossainy ${ }^{\dagger}$, C. M. Abd-Rabou ${ }^{\dagger}$
}

\begin{abstract}
Finite element method (FEM) plays vital role in simulation of many complex problems in fields such as machining, automotive, aerospace, etc. Tool wear is one of the machining problems that is essential in research due to its importance and its effect on product quality and cost. This paper shows the utilization of finite element method in modeling of two dimensional orthogonal cutting process to predict tool wear of uncoated tungsten carbide tool using Abaqus/CAE program. The simulation methodology included the implementation of Johnson-Cook (J-C) model to define the material behavior. Also, the adaptive meshing technique (ALE) is used in simulation the cutting process to combine the advantages of Lagrangian technique that is commonly used in solid mechanics analysis and Eulerian techniques that is commonly used in fluid mechanics analysis. The objective is to predict tool wear location on tool face by using finite element method and compare the results with the experimental work.
\end{abstract}

Keywords: Finite element method (FEM), orthogonal cutting, Johnson-Cook (J-C) model, adaptive meshing or Arbitrary Lagrangian-Eulerian (ALE) technique.

\section{Introduction}

Machining processes are almost the most important mechanical processes in industry nowadays because most of the products get the final shape and size by machining. Therefore, machining has a great interest for the researchers. Tool wear is one of the most affective problems in machining as it effects on the quality of the product and tool life. Due to the negative effects of tool wear in production, researchers do their studies in how to simulate the machining process and predict the tool wear. That helps to optimize the cutting conditions [1] and furthermore the cost of production. The prediction of tool wear can be achieved by two methods, experimental method by using design of experiment technique [2] or numerical method using finite element technique by simulation of the real cutting process and predict the wear [3]. Due to the advent of powerful technology in computers and commercial software packages that is using finite element method (FEM), The FEM has become one of the most essential and powerful tools in the simulation and analysis of cutting process [4] and predict the tool wear.

\section{Orthogonal Cutting}

In machining, there are two types of metal cutting: orthogonal cutting and oblique cutting. The main difference between them is the chip flow direction on tool face. The main difference

Teaching Assistant, Modern Academy for engineering and technology, eng.hatemalisoliman@gmail.com Professor in mechanical design and production engineer, Cairo University, telhossainy@hotmail.com Professor in mechanical design and production engineer, Cairo University, 
between them is the chip flow direction on the tool face. When the chip flows along orthogonal plane perpendicular to the cutting edge, the cutting process is called orthogonal cutting process and when the chip flow deviates from that orthogonal plane that's called oblique cutting. This paper presents pure orthogonal cutting which is the case of orthogonal cutting, moreover the tool cutting edge is perpendicular to the workpiece $\left(\lambda=90^{\circ}\right)$ and the tool geometry with rake angle equal to zero $\left(\mathrm{o}^{\circ}=0^{\circ}\right)$. For example, reduction the length of steel pipe using center lathe machine as shown in Fig. 1.

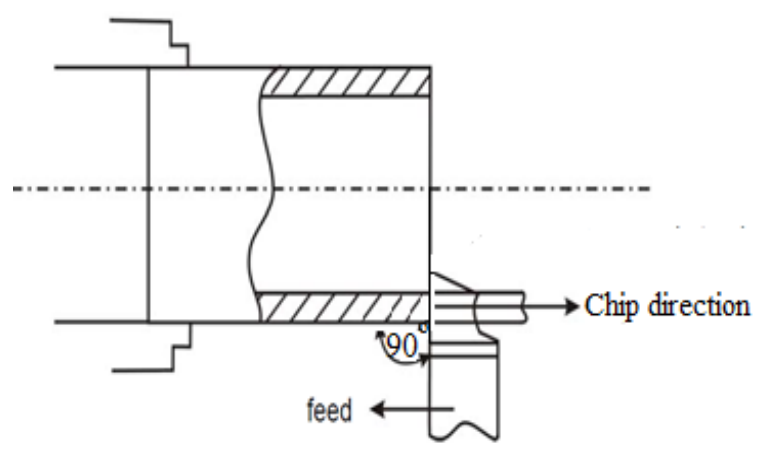

Fig. 1. Pure orthogonal cutting (pipe turning)

\section{Tool Wear Forms and Mechanisms}

The tool wear forms are two basic types: flank wear and crater wear. Flank wear is occurred on the main flank of the tool and it is formed due to rubbing the tool and machined surface. Crater wear is occurred on the tool face and it is formed due to the friction between chip and tool face. Fig. 2 shows the forms of tool wear on single point tool. The tool wear has different mechanisms to be formed. The most common mechanisma are abrasive ,adhesive and diffusibe mechanism. Abrasive wear mechanism is due to the friction between the hard particles in workpiece with the tool. These particles are not from the same workpiece material and more hard than the tool, that's why it affects on the tool wear. It's effect is dominated when the tool is new.Adhesive wear mechanism is due to the rise of the pressure and temperature of cutting process, a part of tool tip may be welded with the workpiece in the cutting zone. The facture of this welding due to the relative motion between the tool and workpiece causes the tool wear. Diffusive wear mechanism is due to the transfer of the tool atoms to workpiece because of concentration difference at high temperature. the rate of atoms transfer increases exponentionally with the temperature rise.

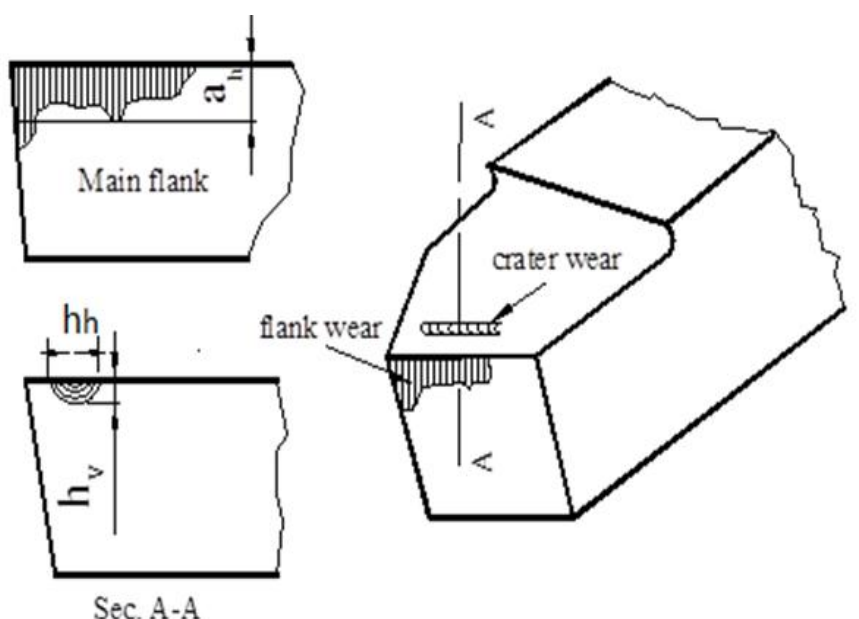

Fig. 2. Forms of tool wear 


\section{Adaptive Meshing}

Finite element method has three common methods to describe the motion of the model: Lagrangian, Eulerian and Arbitrary Lagrangian-Eulerian (ALE) method. In Lagrangian method, the mesh grid moves with the material points. In Eulerian method, the mesh grid is fixed in position and the material moves through the mesh grid. The simulation with Lagrangian technique is without frequent remeshing through analysis and it lacks the ability of simulation models with large deformation as in machining processes. In comparison with the Eulerian method, Eulerian technique can deal with large deformation with a relative ease [5].but its weak point is that the material flow is must be defined before the simulation [6]. Arbitrary Lagrangian-Eulerian method is a combination of Lagrangian technique and Eulerian technique and overcomes the disadvantages of both methods especially in machining processes simulation [4]. ALE allows the material to flow with the mesh grid in arbitrary way trying to converse the initial mesh grading or to improve the aspect ratio of the elements. This method follows adaptive meshing technique, by the meaning that after number of time increments, the ALE technique allows the current mesh to be remeshed by reallocating the nodes to avoid the excessive distortions of the elements to be occurred. Thus, the solution variables (stress, strain, temperature, etc.) are also remapped to this reformed mesh [7]. Fig. 3 shows the difference between the three methods. One of the common problems in the simulation of machining process is that the occurred excessive distortion in elements due to large deformation in workpiece and high strain rate. Thus, adaptive mesh with arbitrary Lagrangian-Eulerian method is commonly used in FE programs to solve and handle with this problem.

(A)
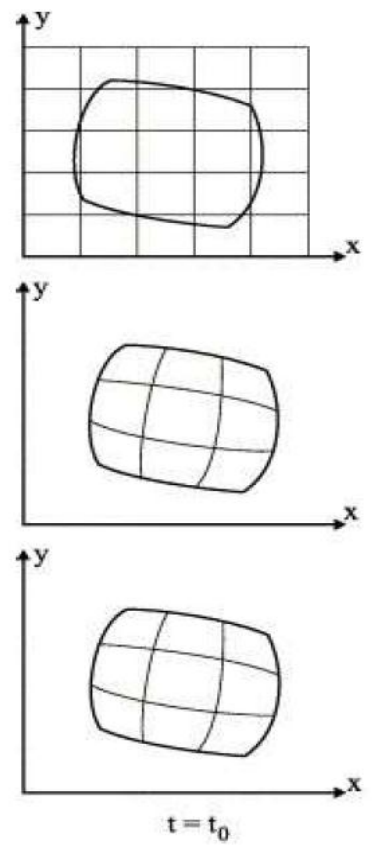

(B)
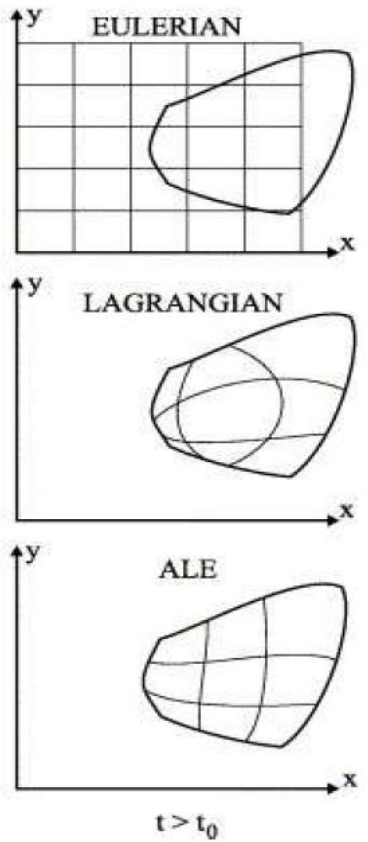

Fig. 3. Difference between Lagrangian, Eulerian and ALE methods

(A) At the beginning of simulation at initial time $\left(t_{0}\right)$.

(B) After running simulation with time period (t) [6]

\section{Johnson- Cook Material Model}

There are many constitutive models such as Oxley material model, Johnson-Cook material model and Zeirilli and Armstrong material model are used in simulation the material beahvior. Comparative study are done between the three models in machining simulation [8]. 
However, the most commonly used is Johnson-Cook (J-C) constitutive model and it is also available in most of the commercial FE programs. Johnson-Cook has two equations; equation (1) describes the plastic behavior of the material deformation), and equation (2) describes the failure behavior of the material. Both of these two equations are implemented in Abaqus /CAE program by defining their parameters into the program to define the material beahvior for the simulation model.

$$
\bar{\sigma}=\left(A+B \bar{\varepsilon}^{n}\right) \quad\left[1+C \ln \left(\frac{\dot{\bar{\varepsilon}}}{\dot{\bar{\varepsilon}}_{0}}\right)\right]\left[1-\left(\frac{T-T_{\text {room }}}{T_{m}-T_{\text {room }}}\right)^{m}\right] \text { (1) }[4]
$$

where, $\bar{\sigma}$ is the equivalent plastic stress $(\mathrm{MPa}), \bar{\varepsilon}$ is the equivalent plastic strain, $\dot{\bar{\varepsilon}}$ is the equivalent plastic strain rate, $\dot{\bar{\varepsilon}}$ is the referenced equivalent plastic strain rate, $\mathrm{T}$ is the temperature $\left({ }^{\circ} \mathrm{C}\right), \mathrm{T}_{\mathrm{m}}$ is the work material melting temperature $\left({ }^{\circ} \mathrm{C}\right), \mathrm{T}_{\text {room }}$ is room temperature $\left({ }^{\circ} \mathrm{C}\right), \mathrm{A}, \mathrm{B}, \mathrm{C}, \mathrm{m}$ and $\mathrm{n}$ are parameters of material.

$$
\bar{\varepsilon}_{f}^{p l}=\left[D_{1}+D_{2} \exp D_{3}\left(\frac{\mathrm{P}}{\sigma}\right)\right]\left[1+D_{4} \ln \left(\frac{\dot{\varepsilon}^{p l}}{\dot{\varepsilon}_{0}}\right)\right]\left[1+D_{5} \frac{\mathrm{T}-\mathrm{T}_{\text {room }}}{\mathrm{T}_{\text {melt }}-\mathrm{T}_{\text {room }}}\right] \quad \text { (2) [4] }
$$

where, $\mathrm{P}$ is the hydrostatic pressure (MPa), $\sigma$ is the effective (undamaged) stress (MPa), D1, D2, D3, D4 and D5 are the failure parameters of the material, and they are determined from experiments and mechanical tests.

\section{Experimental Work}

The experimental work included two stages, first of them is the machining process which is pure orthogonal cutting - shortening- of a mild steel pipes on center lathe machine by using single point tool with tungsten carbide tip at different feed rates $(0.12,0.2,0.26 \mathrm{~mm} / \mathrm{rev})$ and constant velocity $=60 \mathrm{~m} / \mathrm{min}$. It is advisable to choose applicable cutting case to study the tool wear, thus the choice of workpiece material, tool geometry and cutting conditions was chooses from standard data handbooks [9]. Table 1 shows the cutting parameters that are chosen from standard data for the pure orthogonal cutting.

Table 1. The cutting parameters

\begin{tabular}{l|c|c|l}
\hline \multicolumn{1}{c|}{ Materials } & Velocity & Feed rate & \multicolumn{1}{c}{ Tool angles } \\
\hline Tool : Tungsten Carbide (uncoated) & $60 \mathrm{~m} . / \mathrm{min}$. & $0.12,0.2$ and & Rake angle $=0^{\circ}$ \\
Workpiece : low carbon steel pipe & & 0.26 & Relief angle $=10^{\circ}$ \\
& & $\mathrm{mm} . / \mathrm{rev}$. & $\begin{array}{l}\text { Approach angle }=90^{\circ} \\
\text { Inclination angle }=0^{\circ}\end{array}$ \\
\hline \hline
\end{tabular}

The second stage of the experimental work is to predict the crater wear on the carbide tip at the different feed rate values $(0.12,0.2$ and 0.26$)$ by using profilemeter device. This part shows a methodology to predict the tool wear using a surface roughness measuring device (profilemeter).The surface roughness measuring device can be used to measure the irregularity that is caused by cutting action on the surface. Thus, it can be utilized as indirect method for estimating the crater wear on tool face. The estimation can be done by recognizing the difference between the irregularity of the normal surface of the tool tip and the irregularity of the friction surface of the tool tip which was under cutting action as shown in fig. 6 . Due to the friction between the tool and chip, the irregularity frequencies on that friction surface becomes higher than the rest of the tool tip surface. Consequently, when the surface roughness device extracts a profile for the tool surface, it will show two different parts of irregularities, the lower frequency is the normal tool surface irregularity, and the higher 
frequency is the part of the tool surface that was under contact and friction between tool and chip, thus this length can be indication for the crater location and the initial crater wear width. Fig. 5 shows the profilemeter as a tool crater wear predictor.

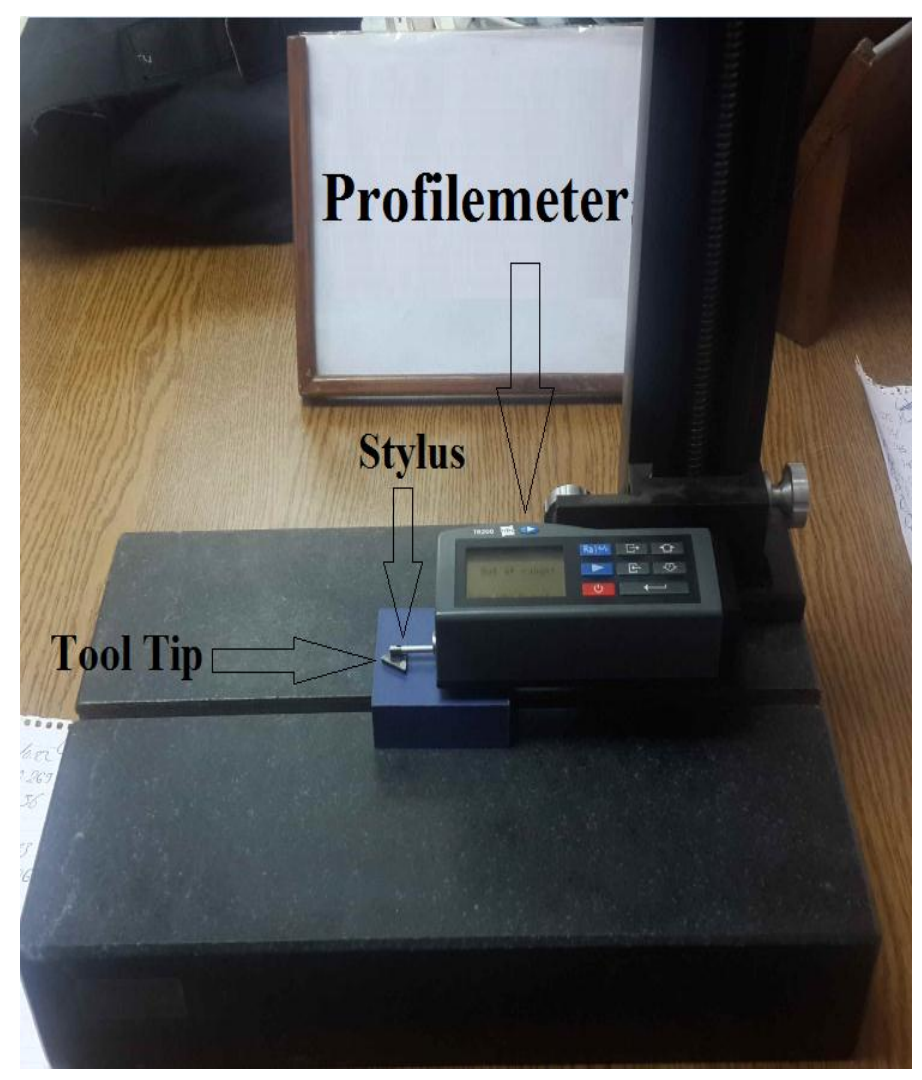

Fig. 5. Profilemeter

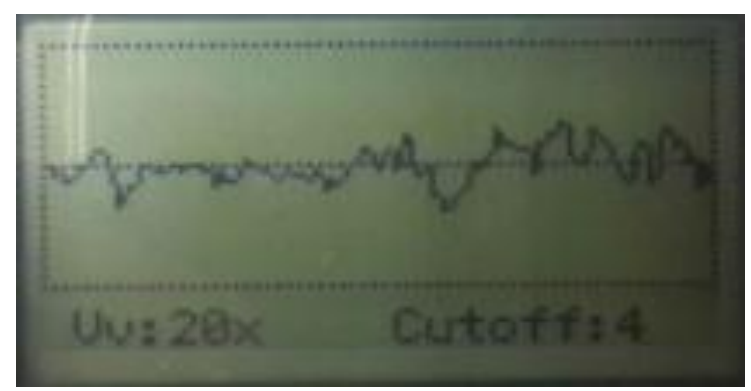

(A) Surface irregularity for normal tool surface

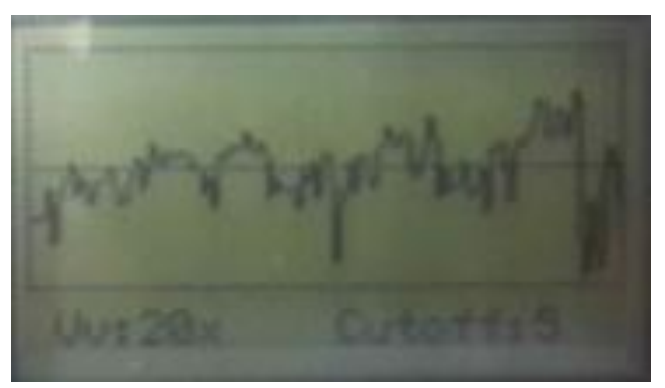

(B) Surface irregularity for friction surface

Fig. 6. The irregularity difference between normal and friction surfaces on tool

\section{Simulation Work}

The simulation work included the modeling of pure orthogonal cutting process using single point tool (uncoated Carbide tool), and applying the finite element method by using ABAQUS /CAE program. ABAQUS /CAE module have high accuracy in simulation nonlinear deformation and contact problems such as in machining processes. 


\section{Model Formulation}

In part module in ABAQUS/CAE program, the tool and workpiece are modeled in 2D planar as deformable parts and shell element. A small portion of workpiece with length $0.015 \mathrm{~m}$ and width $0.001 \mathrm{~m}$ was enough to model workpiece. A small portion of the tool tip with its geometrical angles also was enough to model the tool. Two partitioning lines in workpiece are made - Fig. 7-, one with depth equal to the feed rate value and the other with more than that with sufficient value $=0.003 \mathrm{~m}$ to help in making a dense mesh in the that region of penetration the tool in workpiece [10],[11]. In assembly module, the tool and workpiece are assembled together and a step time is calculated for the model by dividing the workpiece displacement over the cutting velocity (step time $=$ length/ velocity) and then it is implemented into the program step module. Also, the cutting velocity $-60 \mathrm{~m} / \mathrm{min}$ - is defined for the workpiece but the tool keep fixed in its position as boundary conditions for the model as shown in Fig. 7.Contact pairs must be defined between the tool and workpiece into the program interaction module as shown in fig. 8 and with defining the coefficient of friction between them.

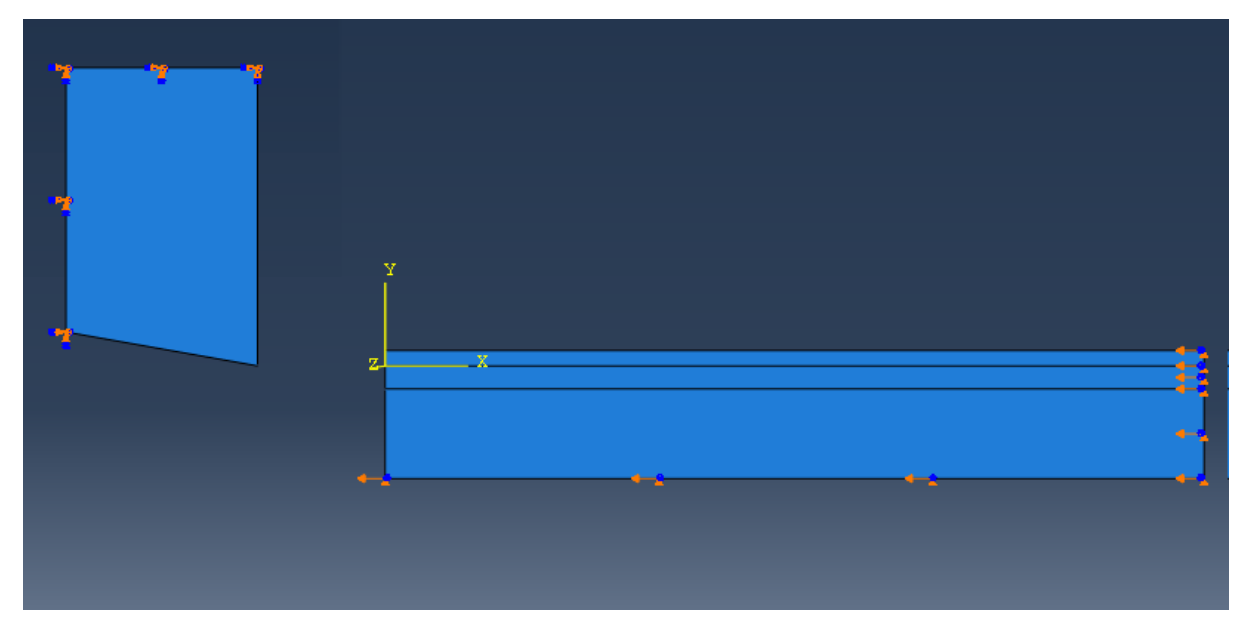

Fig. 7. Boundary conditions for tool and workpiece

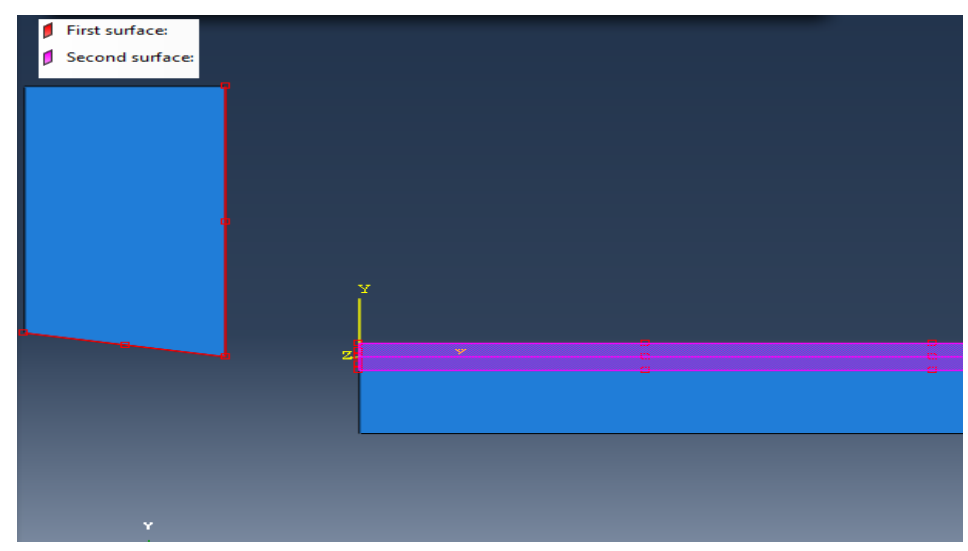

Fig. 8. Contact pairs definition

\section{Materials Definitions}

In material definition module, the parameters of that describe the tool and workpiece material in elastic, plastic and failure behavior are implemented in the program as following: 
Tool is defined as carbide material. The carbide properties are:

- Density $=15630 \mathrm{~kg} / \mathrm{m} 3$

- Elastic properties; Young's Modulus $=550 \mathrm{GPa}$, and Poisson's ratio $=0.234$

- Plastic properties

Table 2. Carbide Tungsten plastic model constants [11]

\begin{tabular}{c|c}
\hline \hline Yield Stress $(\mathrm{MPa})$ & Effective plain strain \\
\hline 419.53 & 0 \\
\hline 1696.90 & 0.000263 \\
\hline 2675.5 & 0.00097364 \\
\hline 3376.5 & 0.003574 \\
\hline 3858.2 & 0.005287 \\
\hline 4178 & 0.007176 \\
\hline 4382.2 & 0.00919 \\
\hline 4504.8 & 0.01129 \\
\hline 4570.1 & 0.013452 \\
\hline 4595.5 & 0.014279 \\
\hline 4597.3 & 0.1 \\
\hline 4597.3 &
\end{tabular}

- Johnson-Cook Damage Model

Table 3. Carbide Tungsten damage model constants [11]

\begin{tabular}{c|c|c|c|c}
\hline \hline $\mathrm{D} 1$ & $\mathrm{D} 2$ & $\mathrm{D} 3$ & $\mathrm{D} 4$ & $\mathrm{D} 5$ \\
\hline 0 & 0.01072 & -1.669 & 0 & 0 \\
\hline \hline
\end{tabular}

Workpiece material is defined as steel ASTM A36, the steel ASTM A36 properties are:

- Density $=7800 \mathrm{~kg} / \mathrm{m} 3$ [42] Wikipedia

- Elastic properties; Young's Modulus $=200 \mathrm{GPa}$, and Poisson's ratio $=0.26$

- Plastic properties

Table 4. Steel A36 plastic Johnson-Cook model constants [12]

\begin{tabular}{c|c|c|c|c|c}
\hline $\begin{array}{c}\mathrm{A} \\
(\mathrm{MPa})\end{array}$ & $\begin{array}{c}\mathrm{B} \\
(\mathrm{MPa})\end{array}$ & $\mathrm{C}$ & $\mathrm{M}$ & $\mathrm{N}$ & $\begin{array}{c}\text { Reference } \\
\text { strain rate }\end{array}$ \\
\hline 286.1 & 500.1 & 0.022 & 0.917 & 0.2282 & 1 \\
\hline \hline
\end{tabular}

- Johnson-Cook Damage Model

Table 5. Steel A36 damage model constants [12]

\begin{tabular}{c|c|c|c|c}
\hline \hline $\mathrm{D} 1$ & $\mathrm{D} 2$ & $\mathrm{D} 3$ & $\mathrm{D} 4$ & $\mathrm{D} 5$ \\
\hline 0.403 & 1.107 & -1.899 & 0.00961 & 0.3 \\
\hline \hline
\end{tabular}




\section{Model Meshing}

In the mesh module, a 4-node bilinear plane strain quadrilateral, reduced integration, and automatic hourglass control (CPE4R) element type was assigned to tool and workpiece from the element library. The number of elements used in the tool and workpiece meshing effects on the simulation accuracy. Series of program runs was carried out to determine the appropriate number of elements of tool and workpiece for each feed rate value that gives suitable simulation of chip forming. The number of elements that gave suitable simulation, stable force results and close to experimental work was 2600 element for workpiece and 200 elements for tool. All feed rates $(0.12,0.2$ and 0.26$)$ simulated by that number of elements but with dense mesh in the penetration zone as in fig. 9 to give accurate results[11].

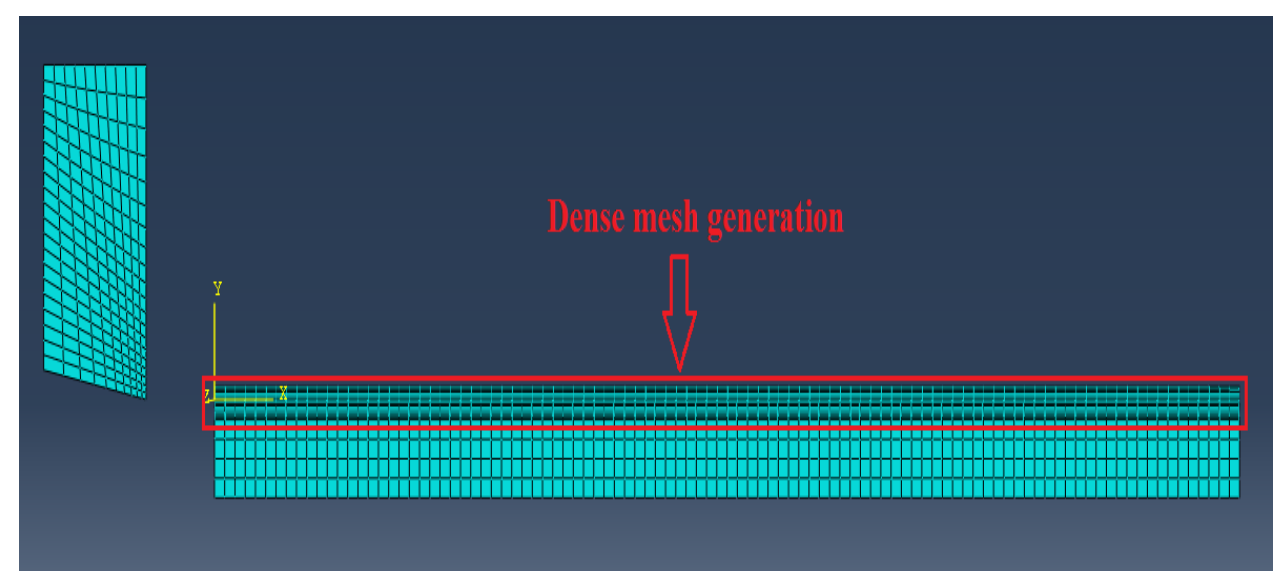

Fig. 9. Model mesh generation

\section{Adaptive Meshing}

Arbitrary Lagrangian-Eulerian (ALE) or Adaptive mesh technique is applied to the model through the step module. In the step module, all requirements of adaptive mesh method such as the ALE adaptive mesh domain -Fig. 10-, constraints and control are defined.

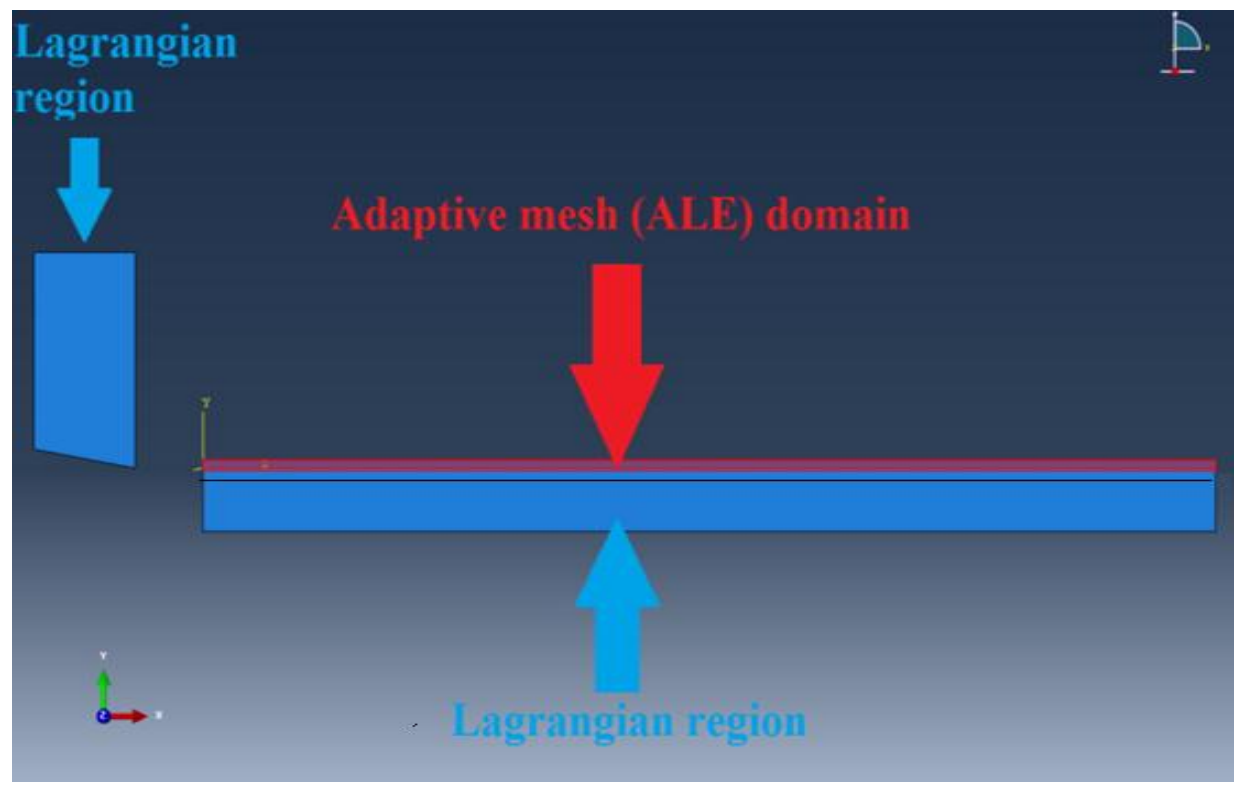

Fig. 10. ALE and Lagrangian region for the model 


\section{Results and Discussion}

\section{Experimental Results}

The profiles for the tool surface are extracted from the profilemeter for the different feed rate values. As shown in fig. 11, the frequencies in the profiles reflect the irregularity of the surface. In each profile, there are two regions with different frequencies. The region with high frequencies which starts from the tool point at the right side reflects the allocation of the crater wear on tool face. Then other region with low frequencies after the previous region indicates the normal tool face surface. The high frequencies region indicates the friction distance between the chip and the tool face and subsequently predicts the crater wear. The values of this region are measured in table 6 . The surfaces although checked by using micrometer and scaled microscope.

An indication of the crater wear shape as the known pool shape is appeared in some profiles as in fig. 11 (A) but it is not generally appeared in the other profiles. The aim of the study was to study the location of the initial crater wear not to study the complete formulation of the crater wear on tool face as it will consume too much time for simulation the real time required for complete crater wear formulation.

Table 6. Experimental results for crater wear prediction

\begin{tabular}{c|c}
\hline \hline $\begin{array}{c}\text { Feed rate } \\
(\mathrm{mm} . / \mathrm{rev} .)\end{array}$ & $\begin{array}{c}\text { Initial crater wear width / } \\
\text { friction surface length } \\
(\mathrm{mm} .)\end{array}$ \\
\hline 0.12 & 0.4 \\
\hline 0.2 & 0.58 \\
\hline 0.25 & 0.65 \\
\hline \hline
\end{tabular}

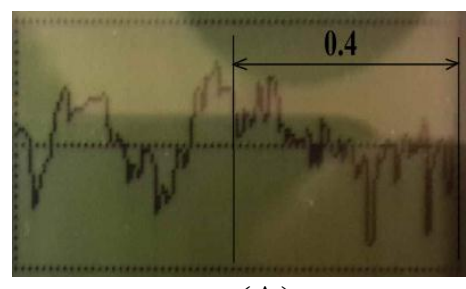

(A)

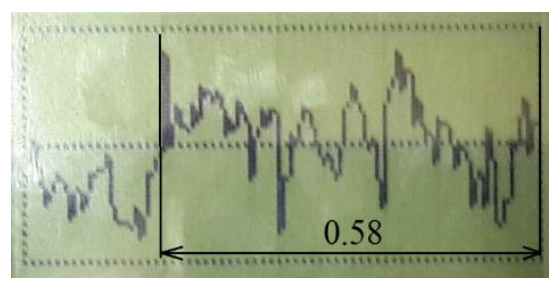

(B)

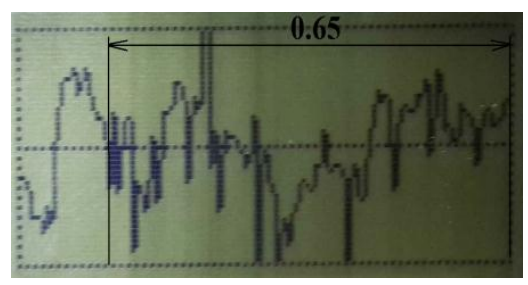

(C)

At feed rate $=0.12 \mathrm{~mm}$. $/$ rev. At feed rate $=0.2 \mathrm{~mm} . / \mathrm{rev}$. At feed rate $=0.25 \mathrm{~mm} . / \mathrm{rev}$. Fig. 11. Tool tip different feed rates $=0.12 \mathrm{~mm}$. $/ \mathrm{rev}$

\section{Simulation Results}

After simulation run, a nodal path is created on the tool face model to indicate the contact pressure values between the chip and tool face. The contact pressure is a reason for the tool wear formulation and thus it can be utilized as a prediction for the crater wear. Figs. 12-14 shows the contact pressure values on the tool face model at different time increments for different feed rate values. The figures show the allocation of the contact pressure along true distance on the tool face starting from the tool point. That allocation of the contact pressure values along the tool face shows the location and the distance of the crater wear but it does not perfectly reflect a real allocation of the crater wear on the tool face at the same instance of the real process time because the simulation process is a quasi-static process. The quasi-static process considers the machining process as a steady process and it is not true. Table 7 , shows the average measured distances of the different time increments as the prediction of crater wear on tool face. 


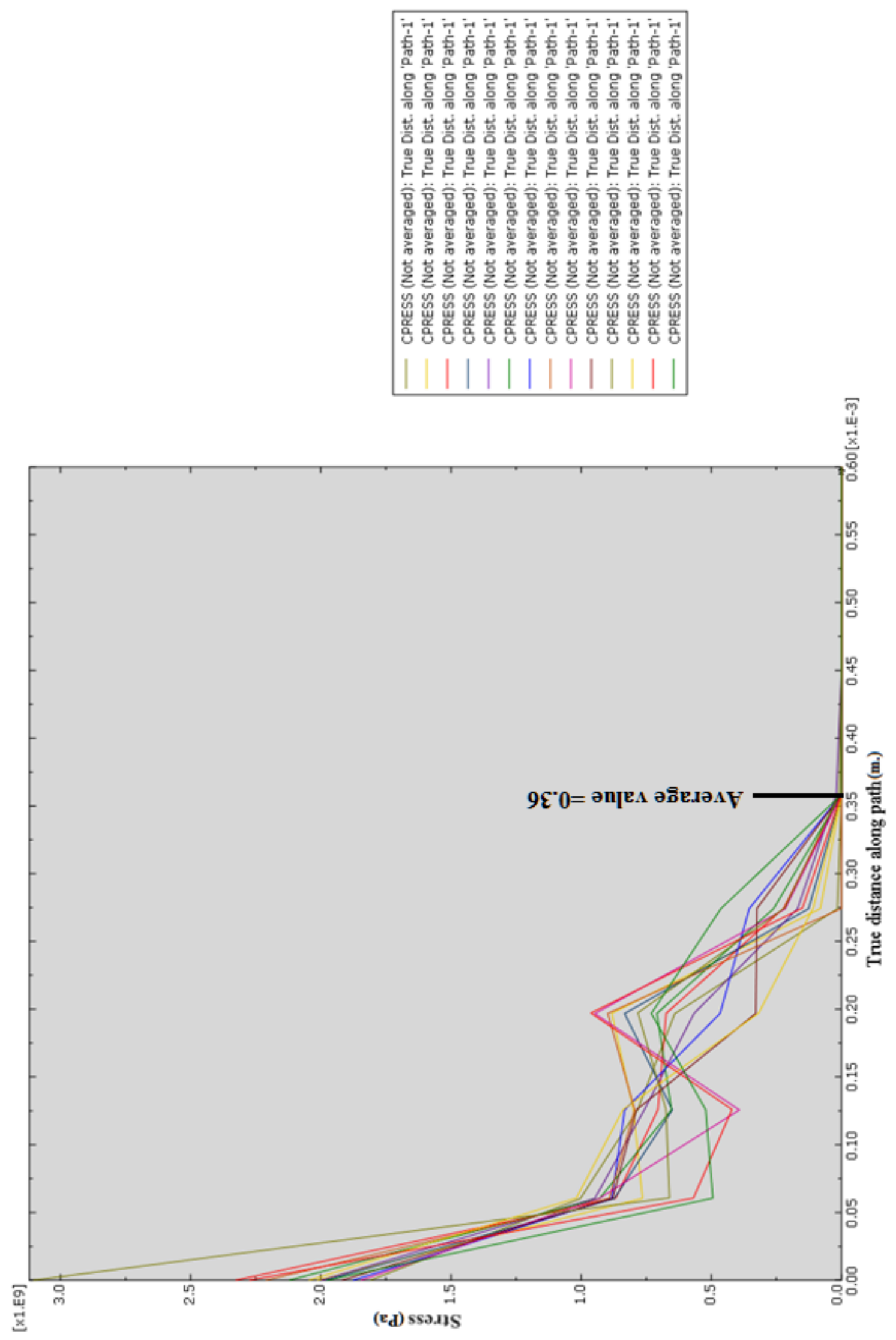

Fig. 12. Contact pressure values at feed rate $=0.12 \mathrm{~mm}$. $/ \mathrm{rev}$. 


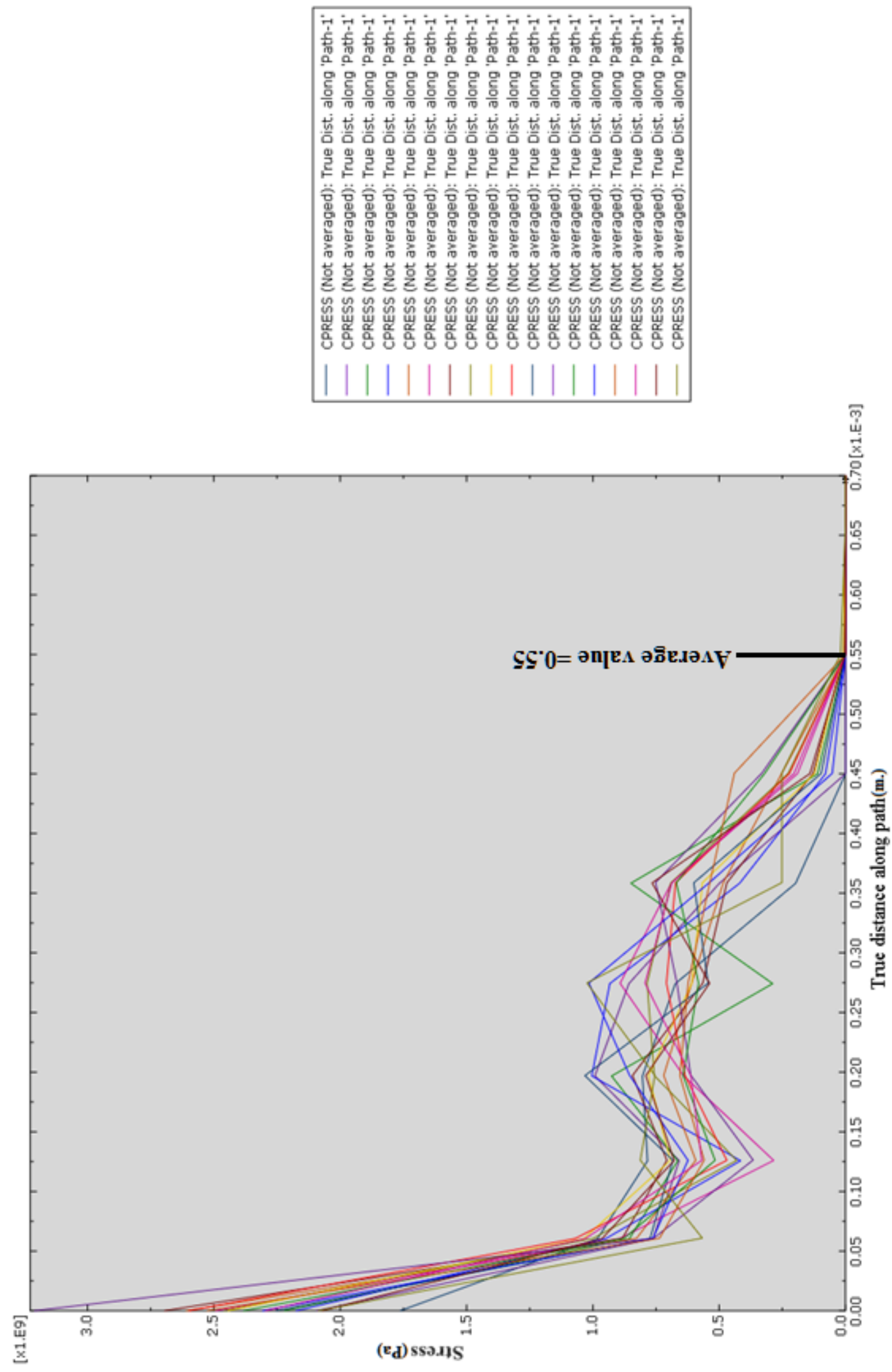

Fig. 13. Contact pressure values at feed rate $=0.2 \mathrm{~mm} . / \mathrm{rev}$. 


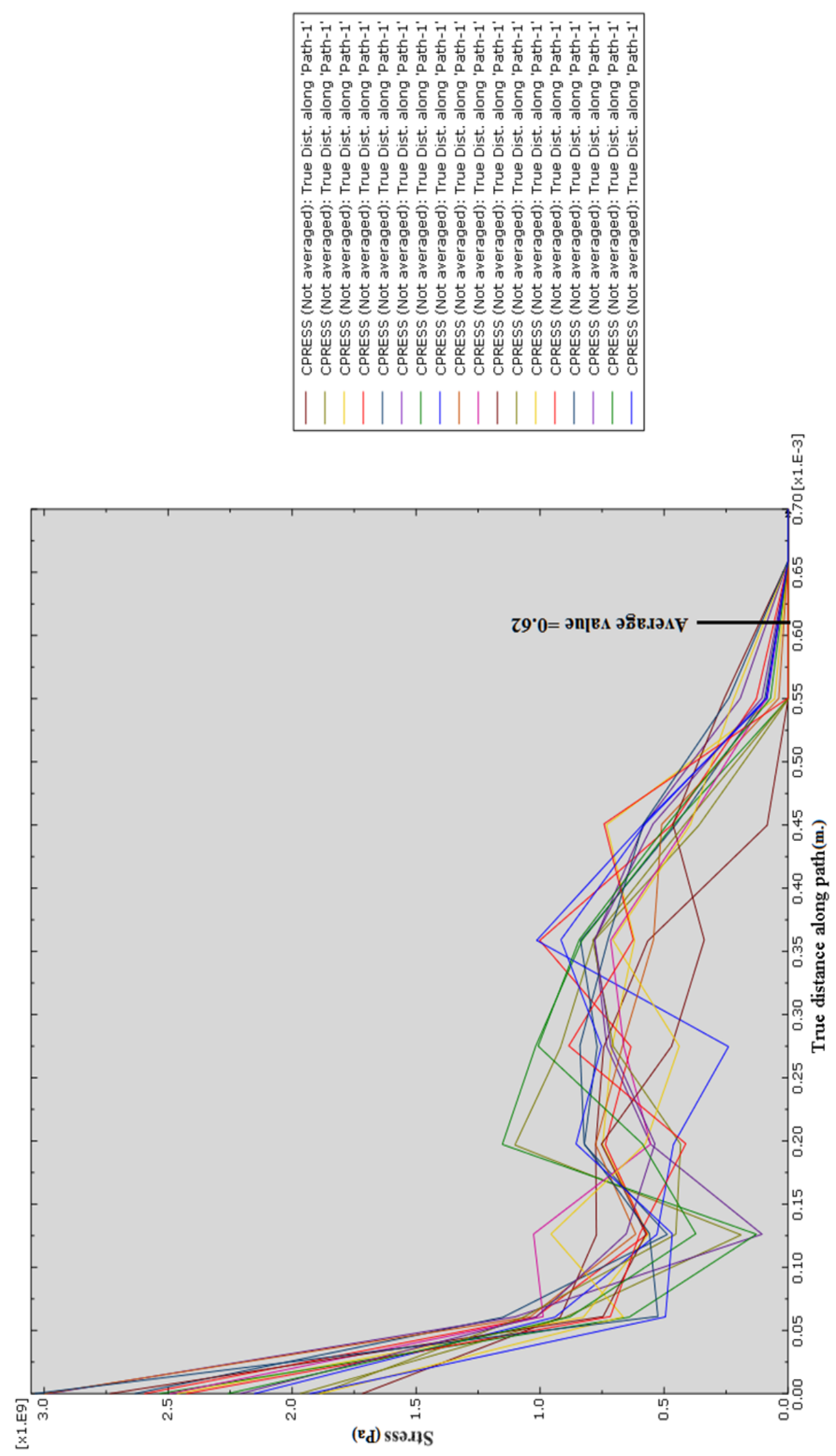

Fig. 14. Contact pressure values at feed rate $=0.25 \mathrm{~mm}$. $/ \mathrm{rev}$. 
Table 7. Simulation results for crater wear prediction

\begin{tabular}{c|c}
\hline \hline $\begin{array}{c}\text { Feed rate } \\
(\mathrm{mm} . / \mathrm{rev} .)\end{array}$ & $\begin{array}{c}\text { Initial crater wear width / contact } \\
\text { pressure length } \\
\text { [Average values] } \\
(\mathrm{mm} .)\end{array}$ \\
\hline 0.12 & 0.36 \\
\hline 0.2 & 0.55 \\
\hline 0.25 & 0.62 \\
\hline
\end{tabular}

\section{Comparison between the Experimental and Simulation Results}

Table 8 , shows the comparison between the crater wear prediction results extracted from the simulation model and the experimental wear results. Also, the error percentage is calculated for the simulation model. The error values show that the simulation results are less than the experimental results and that is due to some reasons. One of them is that the simulation process was mechanical modeling only and not thermo-mechanical. That means the ignorance of the thermal effects between the tool and workpiece of the real cutting process. And as known that the thermal effects contribute in forming of the tool wear. Also another reason for the error is related to material definition. Although Johnson-Cook model is common used in simulation machining processes, but it had some drawbacks in describing the material deformation [13]. One of them is related to how to determine the (J-C) material parameters from the experimental mechanical tests. The split Hopkinson pressure bar (SHPB) is an instrument used for determining Johnson-Cook model. It is used for testing the dynamic stress-strain response of material at different strain rates, as in machining. Unfortunately, the SHPB has drawbacks that can effect on the validity of the results. Finally, one of the most vital reasons for the error of the simulation model is the stability of the cutting process and the chip formation on the tool face in the simulation model. In the fact the cutting process is unstable and the contact length between the chip and the tool slightly varies due to the vibrations of the turning machine which lead to increasing the experimental wear results than the simulation wear results.

Table 8. Comparison between the experimental and simulation results

\begin{tabular}{c|c|c|c}
\hline \hline $\begin{array}{c}\text { Feed rate } \\
(\mathrm{mm} . / \mathrm{rev} .)\end{array}$ & $\begin{array}{c}\text { Experimental crater } \\
\text { wear } \\
(\mathrm{mm} .)\end{array}$ & $\begin{array}{c}\text { Simulation crater } \\
\text { wear } \\
(\mathrm{mm} .)\end{array}$ & $\begin{array}{c}\text { Error } \\
(\%)\end{array}$ \\
\hline 0.12 & 0.4 & 0.36 & $-10 \%$ \\
\hline 0.2 & 0.58 & 0.55 & $-5.2 \%$ \\
\hline 0.25 & 0.65 & 0.62 & $-4.6 \%$ \\
\hline \hline
\end{tabular}

\section{Conclusion}

Finite element method is a powerful simulation tool that can be utilized in many fields such as machining. This paper adopted FEM in one of the most important studies in machining which is the tool wear prediction study. Some points are discussed and presented in this paper to prove the capability of FEM to simulate the orthogonal cutting process and predict the crater wear:

- Arbitrary Lagrangian-Eulerian (ALE) technique that combines the advantages of Lagrangian technique and Eulerian technique to control the distortion of the elements in large deformation as in case of chip formation. 
- Johnson cook model that defines the material behavior in plastic region and the damage behavior of the model.

- Separation line between the chip region and the rest of workpiece in simulation model that helps to reduce the distortion in the separation zone of the chip from workpiece and reduces the analysis time.

Also, it is presented in this study a methodology to predict the crater wear geometry experimentally by using profilemeter device that indicates the irregularity of the tool surface after the occurred friction between the tool and chip.

The future work is to apply the thermo-mechanical modeling after success in dealing with the drawback of measuring the cutting temperature in cutting zone. Also, an improvement of the model is required to be able to simulate the tool wear completely, not only to predict it.

\section{References}

[1] S.R. Das, R.P. Nayak and D. Dhupal, "Optimization of Cutting Parameters on Tool Wear and Workpiece Surface Temperature in Turning of AISI D2 Steel," ", International Journal of Lean Thinking," Vol. 3, Dec., 2012.

[2] Z. Li, H. Zeng and X.Q. Chen, "An experimental study of tool wear and cutting force variation in the end milling of Inconel 718 with coated carbide inserts," ", Journal of Materials Processing Technology," Vol. 180, Dec., 2006, pp. 296-304.

[3] Bin Li, "A Review of Tool Wear Estimation Using Theoretical Analysis and Numerical Simulation Technologies", ", International Journal of Refractory Metals and Hard Materials," Vol. 35, 2012, pp. 143-151.

[4] Amrita Priyadarshini, Surjya K. Pal, and Arun K. Samantaray, "A Finite Element Study of Chip Formation Process in Orthogonal Machining," ", International Journal of Manufacturing," Vol.1, Oct., 2011, pp. 19-45.

[5] Joanne Proudian, "Simulating Residual Stress in Machining; From Post Process Measurement to Pre-Process Predictions," ", M.Sc. thesis, Royal Institute of Technology," Stockholm, Sweden, 2012.

[6] ABAQUS Theory Manual ver. 6.14. (2014).

[7] Jaspers S., "Metal Cutting Mechanics and Material Behaviour," ", Ph.D., Technische Universiteit Eindhoven," Eindhoven, Netherlands, 1999.

[8] Cenk Kilikaslany, "Modeling and simulation of metal cutting by finite element method," ", M.Sc. thesis, Izmir Institute of Technology," Izmir, Turkey, 2009.

[9] T.H.C Childs, K. Maekawa, T. Obikawa and Y.Yamane, 1999, Metal Machining Theory and Applications, Vol X, 1st. edition, Elsevier Ltd, Linacre house, Jordan Hill, Oxford.

[10] Uile Silva, Caio Diniz, Said Rocha, Juliano Filho, Romulo Pereira, Alencar Filho, and Patricia Maia., "Finite Element Modeling for Orthogonal Cutting Process,", ,, SAE Technical Paper," 2015-36-0356.

[11] F. Salvatore, S. Saad, and H. Hamdi, "Modeling and simulation of tool wear during the cutting process," ", 14th CIRP Conference on Modeling of Machining Operations," Turin, Italy, 2013.

[12] Seidt, J.D., Gilat, A., Klein, J.A., Leach, J.R., "High Strain Rate, High Temperature Constitutive and Failure Models for EOD Impact Scenarios," ", Proceedings of the 2007 SEM Annual Conference and Exposition on Experimental and Applied Mechanics, Springfield," MA, June, 2007.

[13] Silva CMA, Rosa PA R and Martins PAF, "Electromagnetic Cam Driven Compression Testing Equipment," ", Experimental Mechanics," Vol.52, 2012, pp. 1211-1222. 